\title{
Fluoretação em Água de Abastecimento e a Saúde Pública
}

\section{Fluoridation in Water Supply and Public Health}

\author{
Joici Rodrigues Silva Prado ${ }^{1}$, Juliana Gervasio Nunes ${ }^{2}$, Suellenn dos Santos Hinnah ${ }^{3}$ e Margarida Marchetto ${ }^{4}$
}

Universidade Federal de Mato Grosso, Faculdade de Arquitetura, Engenharia e Tecnologia, Programa de Pós Graduação em Engenharia de Edificações e Ambiental-PPGEEA. (1, 2 e 3 mestrandas e 4 professora do PPGEEA)

Trabalho recebido em 6/07/14 aceito: 10/09/14 publicado: Novembro de 2014

Resumo: A finalidade da experiência aqui relatada tem por razão investigar o tópico Fluoretação em água usada no abastecimento público e seu objetivo. Neste artigo ainvestigação foi conduzida baseada em dados secundários. Será apresentada uma revisão documental relacionada ao uso do fluoreto e sua aplicação em águas de abastecimento para a prevenção de carie dental na população, além de aspectos gerais e toxicidade do flúor. Serão relatadas as versões de pesquisadores brasileiros e internacionais sobre a dosagem de flúor na água. As autoras reuniram a visão de diferentes linhas de pesquisas e concentram neste documento. Conforme exposto, os procedimentos usados para coletas de dados foram baseados em referências bibliográficas, portanto, serão relatados dados secundários, observações e resultados obtidos por pesquisadores e entidades públicas renomadas na área de tratabilidade da água. Observou-se que, enquanto alguns pesquisadores recomendam a fluoretação da água, outros relatam que o produto é altamente tóxico e não deveria ser usado para este fim.

Palavra-chave: abastecimento público, qualidade da água, saúde bucal

Abstract: The purpose of the experiment reported here is to investigate why the topic Fluoridation in water used for public supply and your goal. In this paper the investigation was conducted based on secondary data. Documentary review related to the use and application of fluoride in drinking water to prevent dental caries in the population will be presented, as well as general aspects and toxicity of fluoride.Versions of Brazilian and international researchers on the dosage of fluoride in water are reported. The purpose of this work is to bring the vision of different lines of research and focus on a document. As stated, the procedures used for data collection were based on references therefore will be reported secondary data, observations and results obtained by researchers and renowned public entities in the area of water treatability. It was observed that, while some investigators recommend water fluoridation, others have reported that the product is highly toxic and should not be used for this purpose.

Keyword: public supply, water quality. oral health

\section{Introdução}

O uso da fluoretação das águas, da educação em saúde, da higiene bucal supervisionada, e das aplicações tópicas de flúor e recuperação e reabilitação da saúde bucal para promoção e proteção à saúde são eixos orientadores de ações da Política Nacional de Saúde Bucal (MARIO JUNIOR \& NARVAI, 2011).

Os fluoretos, forma iônica do elemento químico flúor $(\mathrm{F})$, são os principais durante a fase demineralização dentária sob forma de fluorapatita, o que deixaria o responsáveis pela redução da cárie dentária em países desenvolvidos e também no Brasil. Além da redução da prevalência da cárie, o $\mathrm{F}$ age reduzindo a velocidade de progressão de novas lesões (FUNASA, 2012).

O conceito que implica a necessidade do uso sistêmico (pré-eruptivo, ou seja, no período de formação dos dentes) de flúor, e que diz que a ação anticariogênica se dava pela incorporação do flúor ao esmalte 
esmalte mais resistente a desmineralização, prevaleceu por muito tempo. Como resultado disso o flúor foi muito indicado como medicamento para crianças e gestantes na forma de suplementos (ASSIS et al., 1999; MULLENIX et al., 1995, apud CHIOCA, 2006).

A fluoretação das águas de abastecimento público para prevenir a cárie dentária é uma medida consolidada e sendo amplamente aceita. A Organização Mundial de Saúde desenvolveu um programa para a promoção da fluoretação da água de abastecimento de comunidades, apresentado na $25^{\circ}$ Assembléia Mundial de Saúde, em 1975, que enfatizou a importância de se utilizar o flúor nas concentrações adequadas na água de abastecimento. No entanto, segundo a Funasa (2012) o flúor consumido em excesso apresenta toxidade aguda, referente ao consumo de alta dosagem de flúor de uma única vez, ou crônica, que resulta da ingestão acima do limite adequado por período prolongado ocasionando, a princípio, manchas esbranquiçadas no esmalte dental podendo agravar-se a um grau deformante do elemento.

\section{Histórico da Fluoretação}

As propriedades preventivas do flúor foram descobertas a partir de investigações sobre o seu efeito tóxico no esmalte dentário em desenvolvimento, resultante da sua ingestão. A constatação da fluorose dentária antecedeu a adoção da fluoretação da água de abastecimento público benéfico à saúde bucal. Mediante a observação de tais efeitos e o desejo de investigá-los, desencadeou-se uma série de estudos (BUZALAF,2002, apud FUNASA, 2012).

Em 1931 o químico Petrey analisando a água da cidade de Bauxite (EUA) verificou a presença de flúor na mesma. Amostras de água analisadas de outros locais onde havia pessoas que apresentavam presença de dentes manchados, evidenciaram também, a presença de flúor natural. Concluiu-se, então, a relação entre dentes manchados (fluorose dentária), cárie dentária e água com flúor natural (BUENDIA, 1996, apud FUNASA, 2012).

Após o conhecimento dessa relação, procurou-se estabelecer uma concentração de flúor na água que fosse capaz de produzir o máximo benefício de prevenção de cáries e o mínimo tolerável de fluorose dentária nas populações expostas (EIDELWEIN, 2010).

A comprovação de que, em doses ideais, o flúor seria capaz de reduzir a cárie ocorreram tempos depois, culminando com a fluoretação artificial da água em 1945 (BLEICHER \& FROTA, 2006).

O primeiro caso de fluoretação da água distribuída a população ocorreu na cidade de Grand Rapids (EUA), seguida de Newburg (EUA) e Brantford (Canadá), tendo cada uma, outra cidade controle sem existir flúor em suas águas (BUENDIA, 1996, apud FUNASA, 2012).

A expansão da fluoretação de águas iniciouse em meados do século $\mathrm{XX}$, atingindo países em todo o mundo. No Brasil, em 1952, realizou-se o X Congresso Brasileiro de Higiene, o qual recomendou oficialmente a medida de uso de fluoretação (EIDELWEIN, 2010).

A fluoretação das águas de abastecimento público teve início, no Brasil, em 31 de outubro de 1953, com a implantação deste método em Baixo Guandu, Espírito Santo, pelo Serviço Especial de Saúde Pública, hoje Fundação Nacional de Saúde - Funasa. A escolha desse município foi precedida de um inquérito odontológico que acusou um elevado índice de cárie dental naquela população. $\mathrm{O}$ composto utilizado foi $\mathrm{O}$ Fluossilicato de Sódio (BUENDIA, 1996, apud FUNASA, 2012).

Em 1958 a Organização Mundial da Saúde (OMS), reconheceu a importância da fluoretação e instituiu o Comitê de peritos em fluoretação, cujo parecer em seu primeiro relatório foi favorável, indicando à adição de flúor à água como uma medida de 
saúde pública (RAMIRES e BUZALAF, 2007, apud EIDELWEIN, 2010).

$\mathrm{Na} 25^{\mathrm{a}}$ Assembléia Mundial de Saúde, em 1975, a Organização Mundial da Saúde (OMS) apresentou um programa para a promoção da fluoretação de água de abastecimento de comunidades, obtendo aprovação por unanimidade dos 148 países membros (FUNASA, 2012).

A Federação Dentária Internacional (FDI), Fundação Kellogg (FK) e a Organização Mundial da Saúde (OMS) realizaram, em 1982, a Conferência sobre Fluoretos, onde seus participantes concluíram que a fluoretação da água de abastecimento público é uma medida ideal de saúde pública para o controle da cárie dentária em países onde existem serviços de tratamento de água (VIEGAS et al, 1987, apud FUNASA, 2012).

\section{Legislação da Fluoretação}

Como muitos países, o Brasil também possui uma legislação bem estruturada sobre fluoretação de águas que legitimam a imposição do método. $\mathrm{O}$ primeiro movimento de fluoretar água de abastecimento público se deu no Rio Grande do Sul, no ano de 1944. Este movimento pioneiro resultou na aprovação da Lei Estadual no 3125 , de 18 de junho de 1957, obrigando a fluoretação das águas de abastecimento em todas as localidades operadas pelo Estado e que possuíssem estação de tratamento. A expansão se deu na década de 60 . Por razões conjunturais este programa pioneiro foi interrompido no início dos anos 70 (FUNASA, 2012).

O Congresso Nacional, em 24 de maio de 1974, aprovou a Lei $\mathrm{n}^{\circ}$ 6.050, sancionada posteriormente pelo Presidente da República, General Ernesto Geisel, que determinou no Artigo $1^{\circ}$ que os projetos destinados à construção ou ampliação de sistemas públicos de abastecimento de água, onde haja estação de tratamento, devem incluir previsões e planos relativos à fluoretação de água (FUNASA, 2012).

Essa lei foi regulamentada pelo Decreto $\mathrm{n}^{\circ}$ 76.872, da Presidência da República,em 22 de dezembro de 1975, que estabeleceu em seu Art. $1^{\circ}$, Parágrafo Único, que os sistemas que não possuam estação de tratamento deverão utilizar métodos e processos de fluoretação apropriado ficando o Ministério da Saúde, em seu Art. $2^{\circ}$, autorizado a estabelecer normas e padrões para a fluoretação da água, a serem observadas em todo o território nacional. As normas e padrões a que se refere o Art. $2^{\circ}$ disporão sobre:

- a concentração mínima recomendada e a máxima permitida de íon fluoreto a ser mantida na água dos sistemas públicos de abastecimento;

- métodos de analise e procedimentos para determinação da concentração de íon fluoreto nas águas de consumo público;

- tipo de equipamento e técnicas a serem utilizadas na fluoretação da água.

Segundo o Decreto $n^{\circ} 76.872 / 1975$, Art. $3^{\circ}$, compete aos órgãos responsáveis pelos sistemas públicos de abastecimento de água dos Estados, do Distrito Federal, dos Municípios e dos Territórios o projeto, instalação, operação e manutenção do sistema de fluoretação e, Art. $4^{\circ}$, compete às Secretarias de Saúde ou órgãos equivalentes dos Estados, do Distrito Federal, dos Municípios e dos Territórios examinar e aprovar os planos e estudos de fluoretação contidos nos projetos a que se refere o artigo $1^{\circ}$.

Em seu Art. $8^{\circ}$ o Decreto estabelece que o Ministério da Saúde em colaboração com órgãos oficiais e outros reconhecidos pelo Poder Público promoverá as medidas necessárias à implementação do disposto neste Decreto, inclusive a capacitação de recursos humanos visando a melhorar as condições de saúde dental da população. 
Nesse sentido, o Governo Federal em 2004, lançou o Programa Brasil Sorridente - a saúde bucal levada a sério, cabendo à Funasaa implantação do subcomponente: Fluoretação da água de sistemas públicos de abastecimento (FUNASA, 2012).

As normas e padrões para a fluoretação, a serem seguidos em todo o território nacional foram estabelecidos pela Portaria $n^{\circ}$ 635/Bsb, de 26 de dezembro de 1975 que aprova o referido decreto defendendo a análise diária e mensal da concentração de Flúor nas águas, determinando a necessidade do controle sobre a fluoretação. Além disso, determina o abastecimento contínuo de água distribuída à população, em caráter regular e sem interrupção, dentro das normas e padrão de potabilidade (FUNASA, 2012).

\section{Aspectos Gerais do Flúor}

Encontrado na natureza apenas em compostos (fluoretos) o flúor é o $13^{\circ}$ elemento mais abundante no solo e o $15^{\circ}$ no mar (FUNASA, 2012), no entanto, por ser um elemento litófilo é encontrado em maiores quantidades nas rochas ígneas alcalinas, ácidas e intermediárias (MARIMON, 2006). Isolado, o flúor é um gás que possui odor irritante. Esse elemento apresenta grande afinidade pelos metais bi e tri valentes, como o manganês, ferro e cálcio, característica que favorece sua fixação nos organismos vivos. É o elemento quimicamente mais reativo de todos os íons carregados negativamente (FUNASA, 2012). O flúor é o elemento mais leve do grupo dos halogênios, no entanto, se difere dos outros elementos do grupo por ocorrer como um único isótopo. É o mais eletronegativo dos elementos químicos e em solução forma íons fluoreto $\left(\mathrm{F}^{-}\right)$(LUCAS, 1988, apud MARIMON, 2006).

Apresentando coloração amarela clara, o flúor, é altamente corrosivo, reagindo com praticamente todas as substâncias orgânicas e inorgânicas. Possui odor pungente e densidade no estado liquido de 1,512 enquanto sua entalpia de dissociação é de 37,7 Kcal (MARIMON, 2006).

É um elemento químico que pode ser encontrado, de forma natural na água, podendo ser também adicionado à água de abastecimento público, em produtos dentais(dentifrício e soluções para bochecho) e alimentos,em medicamentos (complexos vitamínicos), além disso, possui ação anticariogênica (CHIOCA, 2007).

A explicação da presença de flúor nos alimentos se dá ao fato de os fluoretos, compostos químicos formados pela combinação com outros elementos, serem encontrados no solo, ar, água, plantas e vida animal. Ainda assim, o que o ser humano ingere, em média é $0,3 \mathrm{mg}$ de Flúor por dia. O conteúdo de Flúor na superfície terrestre varia de 20-500 ppm, aumentando nas camadas mais profundas, podendo chegar até $8.300 \mathrm{ppm}$, conferindo uma maior concentração de Flúor às águas subterrâneas (FUNASA, 2012).

Nos solos o flúor e encontrado em pequenas concentrações e sua mobilidade dependente da forma química, velocidade de deposição, química do solo e clima, $\mathrm{pH}$ e por processos de adsorção e dissorção (MARIMON, 2006). $\mathrm{Na}$ maioria dos ambientes a fluorita é o principal mineral que controla a geoquímica do fluoreto nas águas. A concentração de $\mathrm{F}^{-}$ esta limitada pela solubilidade da fluorita. Trocas iônicas envolvendo argilas resultam na diminuição do $\mathrm{Ca}_{2}{ }^{+}$na água elevando a concentração de fluoreto (ANDREAZZINI ET AL, 2014).

As concentrações de fluoreto nas águas naturais são controladas por fatores como: temperatura, $\mathrm{pH}$, presença de íons e coloides complexantes, solubilidade dos minerais que contém flúor, capacidade de troca iônica dos materiais do aqüífero, tamanho e tipo de formações geológicas e tempo que as águas estão em contato com uma formação particular ( AMPABIRE ET AL., 1997 apud ANDREAZZINI ET AL, 2014).

Sobre isso Marimon (2006) afirmou que a contenção de fluoreto nas águas superficiais 
e subterrâneas ocorre geralmente em baixas concentrações. No entanto, essas concentrações podem aumentar consideravelmente como resultado do intemperismo de rochas e o aporte a partir de fontes antropogênicas.

No ar, a concentração de fluoretos se dá pela presença de "aerossóis" (pó de solos) ricos em Flúor, resíduos industriais gasosos, combustão de carvão e gases emitidos em zonas de atividades vulcânicas, podendo variar de 0,05 - 1,90 mg de Flúor/m³. Níveis de até $1,4 \mathrm{mg}$ de Flúor $/ \mathrm{m}^{3}$ foram registrados dentro de fábricas e de $0,2 \mathrm{mg}$ de Flúor $/ \mathrm{m}^{3}$ nas imediações (FUNASA, 2012).

A população, como visto, esta exposta ao contato com o flúor e, segundo a Funasa(2012), na ingestão o sal de Flúor é rapidamente veiculado através da corrente sanguínea, ocorrendo uma deposição de íons fluoretos nos ossos e dentes. A parcela não absorvida, $90 \%$, é eliminada normalmente pelas vias urinárias, ocorrendo também por meio das fezes, suor e fluidos gengivais.

A ocorrência do flúor na cavidade bucal devido à fluoretação da água (flúor tópico) não é capaz de controlar completamente a ocorrência de cárie, mas reduz em torno de $50 \%$, o que torna a fluoretação uma medida econômica, capaz de reduzir significativamente a cárie de uma comunidade, e ainda, altamente efetiva do ponto de vista do administrador de saúde, pois um indivíduo recebe um composto de flúor que pode oferecer proteção para a cárie (RAMIRES \& BUZALAF, 2007).

De acordo com a Funasa(2012), o maior grau de proteção permanece constantemente na boca uma vez que a ingestão sistemática e posterior retorno ao meio bucal pela saliva tem função tópica na superfície do dente. A efetividade do flúor sistêmico se deve à combinação de três fatores: o fortalecimento do esmalte pela redução da sua solubilidade perante o ataque ácido, inibindo a desmineralização; o favorecimento da remineralização; e a mudança na ecologia bucal pela diminuição do número e do potencial cariogênico dos microrganismos. Com ação preventivo-terapêutica o flúor esta sujeito à dinâmica constante de trocas minerais estabelecidas entre saliva e esmalte dentárionão oferecendo assim resistência permanente à cárie, uma vez que: as pessoas privadas da exposição do flúor voltam a ter as mesmas chances de desenvolver cárie dental que aquelas nunca expostas (FUNASA, 2012).

\section{Cinética do Flúor}

Conforme Whitford (1990), apud Chioca (2007), o flúor pode ser absorvido através da mucosa bucal, especialmente em soluções ácidas,mas a maior taxa de absorção do flúor ocorre no trato gastrointestinal. Os compostos solúveis de flúor na água e alimentos quando ingeridos sofrem dissociação iônica em função do ácido clorídrico produzido no estômago (FUNASA, 2012). A redução do pH acelera a absorção, logo a acidez estomacal facilita a absorção e conseqüentemente os efeitos tóxicos (SILVA, 2003). O monofluorfosfatodissódico (MFP) causa menos irritação à mucosa gástrica que o fluoreto de sódio porque é absorvido após hidrolise enzimática das moléculas por fosfatases(WHITFORD et al., 1990, apud CHIOCA, 2007).

Por intermédio do plasma sanguíneo o flúor circula por todo o organismo. Após três horas $70 \%$ é eliminado pela urina, $15 \%$ pelas fezes e 5\% pelo suor. Apenas $10 \%$ do Flúor ingerido é assimilado pelo organismo. Essa pequena parte circula nos fluídos intra e extracelulares fixando-se nos tecido duros: ossos e dentes em formação. O flúor não se fixa em tecidos moles (BUENDIA, 1996, apud, FUNASA, 2012). 


\section{Toxicidade do Flúor}

A toxicidade do flúor tem gerado intensa polêmica em torno de seus benefícios e malefícios.

\section{Para Chioca (2007):}

A variação dos níveis na água e a variedade de fontes de flúor podem proporcionar um consumo elevado, o que pode atingir nível tóxico. Exceto em relação à fluorose dentária e óssea, a literatura a respeito da toxicidade do flúor é restrita, existindo poucos relatos de intoxicação em humanos, que sugerem que a exposição crônica ao flúor pode afetar funções cerebrais, particularmente a memória.

Há relatos de casos de intoxicação com flúor, por ingestão de produtos dentais, que levaram a morte (CHIOCA, 2006). O manual da Funasa (2012) diz que mesmo com o consenso da relação existente entre o uso do Flúor e a redução de cárie dentária, é possível afirmar que o flúor é uma substância tóxica quando ingerido em altas doses. Os efeitos desencadeiam distúrbios gástricos reversíveis e redução temporária da capacidade urinária, fluorose dentária ou esquelética e, eventualmente, até mesmo a morte, uma vez que, estão diretamente relacionados à dose, tempo de ingestão e idade (WHITFORD, 1996).

Chioca (2007) ainda afirmou sobre a toxicidade crônica:

O flúor ingerido em baixas doses, por período prolongado, está relacionado com alterações nas estruturas dentais e ósseas. O íon flúor atua de maneira tóxica precipitando o cálcio, elemento essencial a várias funções fisiológicas, em particular aos tecidos musculares e nervosos. Na toxicidade crônica do flúor, pela sua afinidade com os fosfatos, forma a fluorapatita; e com o cálcio forma o fluoreto de cálcio, pouco solúvel. Sendo assim, os tecidos ósseo e dentário portadores de uma elevada porcentagem de cálcio e fosfato, podem sofrer os efeitos tóxicos do flúor, resultando em alterações dentárias, como fluorose e alterações óssea, como a hipercalcificação, chamada osteopetrose ou osteosclerose, tornando os ossos frágeis (FABRE; TRUHAUT, 1971; HARINARAYAN et al., 2006). No caso da fluorose as células responsáveis pela formação e secreção do esmalte, os ameloblastos, são sensíveis ao flúor, principalmente nos estágio iniciais, da maturação do esmalte (BROWNE et al., 2005).

A neurotoxicidade causada pelo flúor resulta em danos tóxicos ao sistema. Isso e possível porque o uso com finalidade terapêutica em grandes quantidades ou disponível em altas concentrações no meio ambiente pode transpor a barreira hematoencefalica (SPITTLE, 1994).

As populações que consomem água na forma natural com elevado teor de fluoreto ficam sujeitas a moléstias, tornando-se alvo importante de prevenção e controle de saúde publica. Esta doença tem sido verificada em diversos países, onde pesquisas fazem relação com o consumo de águas subterrâneas com teores elevados de fluoreto (MARIMON, 2007).

A Organização Mundial de Saúde - OMS recomenda para prevenção de cáries que seja consumido de 1,0 a 3,0 mg/dia de flúor por ser humano, Isso implica em um consumo de 0,5 a $1,5 \mathrm{mg} / \mathrm{L}-1$ de fluoretos na água para beber e para o preparo de alimentos o que da uma estimativa de $2 \mathrm{~L}$ agua/adulto/dia. Deve se considerar ainda que as condições do clima e hábitos da população alteram as concentrações. $\mathrm{O}$ teor de flúor estabelecido como ótimo na água potável varia entre 0,7 a 
1,2 $\mathrm{mg} / \mathrm{l}-1$, conforme as medias de temperaturas anuais (WHO, 2002).

A concentração de Flúor no sangue de um pessoa em jejum que faz ingestão de água fluoretada é cerca de 0,019mg F/L. Em regiões com altas concentrações de Flúor na água de abastecimento, são observadas importantes variações na concentração plasmática de Flúor dos habitantes (FUNASA, 2012).

Diante dessas colocações Ramires \&Buzalaf (2007) afirmaram:

A fluoretação da água é reconhecida como um importante fator para o declínio da prevalência da cárie dentária. Portanto, além de ser mantida, deve ser monitorada, a fim de que o teor de flúor seja mantido dentro dos padrões adequados para o controle da cárie e prevenção da fluorose dentária. Programas de políticas públicas devem garantir a implantação da fluoretação das águas em municípios com sistemas de tratamento, possibilitando à população o acesso aos benefícios do flúor.

Fluoretação da Água para Consumo Humano

Visão geral : Adicionando o flúor na água de abastecimento evita-se a ocorrência de cárie na população quando consumida de forma continua. Segundo Funasa (2012), [...] reduz a prevalência de cárie dental entre $50 \%$ e $65 \%$ em populações sob exposição contínua desde o nascimento, por um período de aproximadamente dez anos de ingestão da dose ótima. É um processo seguro, econômico e adequado.

O uso do flúor em saúde pública, sob a forma de fluoreto, é considerado o principal fator de proteção, decisivo para a obtenção de expressiva redução na prevalência da cárie (ALVES et al., 2012).
Assim os meios seguros para a utilização do fluoreto são de duas formas: os usos contínuos em creme dental e o consumo de água de abastecimento estando com concentrações entre 0,8 e 0,6 , como mostram diversos autores.

\section{Requisitos Básicos para Implantação}

Deve-se pensar no tipo de fluido bombeado, no tipo de sal de fluoreto a escolher, porque a sua densidade, viscosidade e a concentração de produtos podem variar aumentando ou diminuindo a quantidade utilizada de produto, fatores envolvidos com o armazenamento do produto na casa de química de uma Estação de Tratamento de Água de Abastecimento - ETA e o tipo de dosador a ser utilizado.

Os sais de fluoretos mais utilizados são

- Fluossilicato de Sódio - $\mathrm{Na}_{2} \mathrm{SiF}_{6}$

- Ácido Fluossilícico - $\mathrm{H}_{2} \mathrm{SiF}_{6}$

- Fluoreto de Sódio - NaF

- Fluoreto de Cálcio ou Fluorita $\mathrm{CaF}_{2}$

$\mathrm{Na}$ Portaria $\mathrm{n}^{\circ}$ 635/Bsb. de 26 de dezembro de 1975, como é mostrado na tabela 1 a seguir, são apresentados os tipos de sais de fluoreto com suas devidas características.

A concentração em $\mathrm{mg} / \mathrm{L}$ recomendada de íon fluoreto nas águas de abastecimento público é obtida abaixo, conforme a Portaria n 635/ Bsb, de 26 de dezembro de 1975:

$$
\begin{aligned}
& \text { C mg/ } \mathbf{L}=\mathbf{2 2 , 2} / \mathbf{E} \\
& \text { Em que: } \\
& \mathrm{E}=10,3+0,725 \mathrm{~T} \\
& \mathrm{~T}=\text { média de Temperaturas }
\end{aligned}
$$

máximas diárias observadas durante um período mínimode 1 ano (recomendado 5 anos) em graus centígrados. Assim.

a) Levantamento do índice de CPO-D ( $C=$ Cariados; $P=$ Perdidos; $O=$ Obturados; $D=$ Dentes $)$

b) Informações técnicas do sistema de abastecimento de água; Tipo de 
manancial; Vazão do Sistema de Abastecimento de Água; População abastecida; Número de ligações; Tempo de funcionamento; Tipo de tratamento; Formas de reservação; Teor natural de íon fluoreto. c) Teor ideal de íon fluoreto a ser aplicado;

d) Escolha do produto;

e) Escolha do equipamento;

f) Definição do ponto de aplicação;

g) Controle e Freqüência.

Tabela 1 - Tipos de sais de fluoreto com suas devidas características.

\begin{tabular}{|c|c|c|c|c|}
\hline Características & $\begin{array}{c}\text { Fluoreto de } \\
\text { Cálcio (Fluorita) } \\
\text { CaF }_{2}\end{array}$ & $\begin{array}{l}\text { Fluossilicato de } \\
\text { Sódio } \mathrm{Na}_{2} \mathrm{SiF}_{6}\end{array}$ & $\begin{array}{l}\text { Fluoreto do Sódio } \\
\text { Na F }\end{array}$ & $\begin{array}{l}\text { Ácido Fluossilícico } \\
\qquad \mathrm{H}_{2} \mathrm{SiF}_{6}\end{array}$ \\
\hline Forma & Pó & Pó ou cristais finos & Pó ou cristal & Líquido \\
\hline Peso Molecular & 78,08 & 188,05 & 42,0 & 144,08 \\
\hline Pureza Comercial \% & 85 a 98 & $98 \mathrm{a} 99$ & $90 \mathrm{a} 98$ & 2230 \\
\hline $\begin{array}{l}\text { Solubilidade } \mathrm{gr} / 100 \\
\operatorname{gr}\left(25 .{ }^{\circ} \mathrm{C}\right)\end{array}$ & 0,0016 & 0,762 & 4,05 & \\
\hline pH da solução saturada & 6,7 & 3,5 & 7,6 & 1,2 (solução $1 \%$ ) \\
\hline $\begin{array}{l}\text { Íon Fluoreto em } \%(100 \% \\
\text { puro) }\end{array}$ & 48,8 & 60,7 & 42,25 & 79,2 \\
\hline
\end{tabular}

Fonte:Portaria n ${ }^{\circ}$ 635/Bsb. de 26 de dezembro de 1975.

Os métodos de análises empregados para o parâmetro de fluoreto em águas podem ser:

\section{- Método da Destilação}

Preliminar: Por meio de destilação, o íon fluoreto pode ser separado dos outros elementos existentes nas águas, na forma de ácido Fluossilícico ou Fluorícico ou Fluorídrico. A recuperação quantitativa do fluoreto se obtém usando amostras relativamente grandes e sob altas temperaturas.

- $\quad$ Método Spadns: é utilizado o espectrofotômetro de comprimento de onda de $580 \mathrm{~nm}$ e no procedimento uma das soluções para o método é a Solução SPADNS.

\section{- $\quad$ Método Visual da Alizarina: \\ Reagente Zircônio-Alizanina, no final desenvolve coloração, ele é um método titulométrico.}

- Método Eletrométrico: Por meio de eletrodo específico que pode ser acoplado a um potenciômetro com escala expandida em milivolts, o elemento cristal de fluoretos estabelecerá um potencial pela presença de íons fluoretos. Essa medição serve para medir atividade ou concentração de fluoreto em amostra de água mediante uma curva padrão apropriada.

Fluoretação da Água de Abastecimento no Mundo

Atualmente é possível observar a existência de países que adotam a fluoretação da água e outros que a interromperam ou nunca a utilizaram (EIDELWEIN, 2010). Em 2005 cerca de 40 países utilizavam sistemas artificiais de fluoretação da água. Entretanto, em alguns casos, apenas uma pequena proporção da população é coberta pelo sistema (MULLEN, 2005).

Muitas regiões não adotam a fluoretação da água por já apresentarem águas naturalmente fluoretadas. Áreas com ocorrência de flúor natural na água são: Oriente Médio e Sul da Ásia, Leste africano, a faixa que abrange Turquia, Iraque, Irã, Afeganistão, Índia, China e norte da Tailândia, e algumas regiões do Japão e do continente americano (EIDELWEIN, 2010). 
Pode-se citar alguns Países que adotam a medida: Brasil, Argentina, Chile Colômbia, Guiana, Panamá, Estados Unidos, Guatemala, Canadá, África do Sul, Líbia, Espanha, República da Irlanda, Reino Unido, Grécia, Bulgária, Brunei, Fiji, Vietnã, Malásia, Filipinas, Austrália, Nova Zelândia, República da Coréia, Hong Kong e Singapura (EIDELWEIN, 2010; MULLEN, 2005; THE BRITISH FLUORIDATION SOCIETY, 2004).

Alguns países que não adotam a fluoretação da água são: Uruguai, Venezuela, Haiti, México, Alemanha, França, Países Baixos, Áustria, Suíça, Bélgica, Itália, Noruega, Finlândia, Dinamarca, Suécia, Polônia, Eslovênia, Hungria, Croácia, República Tcheca, Irã, Índia, Sri Lanka, China, Taiwan, Japão, Senegal, Nigéria, Gabão, Namíbia, República Democrática do Congo, Tanzânia, Zâmbia e Zimbábue (EIDELWEIN, 2010; MULLEN, 2005; THE BRITISH FLUORIDATION SOCIETY, 2004).

\section{Considerações Finais}

O uso de flúor na água de abastecimento é considerado por uma linha de pesquisadores, como um processo seguro, econômico e adequado, que previne e evita a ocorrência de cárie na população, quando consumido de forma continua reduz a prevalência de cárie dental entre $50 \%$ e $65 \%$, em populações sob exposição contínua desde o nascimento, por um período de aproximadamente dez anos de ingestão da dose ótima.

Para esta linha de pensamento, "O uso do flúor em saúde pública, sob a forma de fluoreto, é considerado o principal fator de proteção, decisivo para a obtenção de expressiva redução na prevalência da cárie" Por outra visão científica, a toxicidade do flúor tem gerado intensa polêmica em torno de seus benefícios e malefícios, inclusive casos de intoxicação com flúor, por ingestão de produtos dentais, que levaram a óbito.
Pesquisadores e órgãos de saúde pública Brasileiros relatam que mesmo com o consenso da relação existente entre o uso do Flúor e a redução de cárie dentária, é possível afirmar que o flúor é uma substância tóxica quando ingerido em doses elevadas. Os efeitos desencadeiam distúrbios gástricos reversíveis e redução temporária da capacidade urinária, fluorose dentária ou esquelética e, eventualmente, até mesmo a morte, uma vez que, estão diretamente relacionados à dose, tempo de ingestão e idade.

\section{Referências}

ANDREAZZINI, M.J.; Figueiredo, B.R.; LICHT,O.A.B.Geoquímica do flúor em aguas e sedimentos fluviais da região de Cerro Azul, estado do Paraná: Definição de áreas de risco para consumo humano.CPRM. Disponível em:<http://www.cprm.gov.br/publique/medi a/geo_med18.pdf $>$. Acesso em: 05 de jun., 2014.

ASSIS, G.F.; BUZALAF M.A.R.; FARIA F.A.C.; GRANJEIRO J.M.; TORRES S.A.; LARA V.S.; OLIVEIRA D.T.; Mecanismos biológicos e influência de fatores ambientais na fluorose dentária e a participação do flúor na prevenção da cárie. RevFacOdontol Bauru, v.7, n.3/4, p.63-70, 1999.

BLEICHER, L; FROTA, F.H.S. Fluoretação da Água: uma questão de política pública - o caso do Estado do Ceará. Revista Ciência e Saúde Coletiva. Rio de Janeiro, vol. 11, $\mathrm{n}^{\mathrm{o}}$ 1, jan/mar 2006.

BRASIL. Decreto $\mathbf{N}^{\mathbf{0}} \mathbf{7 6 . 8 7 2}$ de 22 de Dezembro de 1975. Regulamenta a Lei $\mathrm{n}^{\circ}$ 6.050/74, que dispõe sobre a fluoretação da água. Brasília, 1975. 
BRASIL. Fundação Nacional de Saúde. Manual de Fluoretação da Água para Consumo Humano/ Fundação Nacional de Saúde - Brasília: Funasa, 2012. 72 p.

BRASIL. Ministério da Saúde. Secretaria de Atenção à saúde. Departamento de Atenção Básica. Guia de recomendações para o uso de fluoretos no Brasil / Ministério da Saúde, Secretaria de Atenção à Saúde, Departamento de Atenção Básica - Brasília: Ministério da Saúde, 2009.

BROWNE, D.; WHELTON, H.; O'MULLANE, D. Fluoride metabolism and fluorosis.J Dent, v. 33, p. 177-86, 2005.

CHIOCA, Lea Rosa. Ingestão Crônica de Flúor induz prejuízo nos testes de habituação e esquiva ativa em ratos. Curitiba, 2007. Dissertação apresentada Universidade Federal do Paraná. Programa de pós-graduação em Farmacologia.

EIDELWEIN, C. Panorama, benefícios e controvérsias da fluoretação da água de abastecimento público no Brasil e no mundo: uma revisão de literatura. Universidade Federal do Rio Grande do Sul. Porto Alegre, 2010.

FABRE, R.; TRUHAUT, R. Tóxicos Fixos de Natureza Mineral. In: Toxicologia. Lisboa: Fundação Calouste Gulbenkian. 1971. p. 630-642.

HARINARAYAN, C.V.; KOCHUPILLAI, N.; MADHU, S.V.; GUPTA, N.; MEUNIER, Fluorotoxicmetabolicbonedisease: Anosteorenal syndrome caused by excess fluoride ingestion in thetropics. Bone, v.39, p.90714,2006

LUCAS, J. Fluorine in the Natural Environment. Journal of fluorine Chemistry, 41: 1-88, 1998.
MARIMON, Maria Paula Casagrande. O flúor nas aguas subterrâneas da formação Santa Maria, na região de Santa Cruz do Sul e Venâncio Aires, RS, Brasil. Porto Alegre, 2006. Tese de Doutorado apresentada Universidade Federal do Rio Grande do Sul. Programa de Geociências.Disponível em <http://www.lume.ufrgs.br/bitstream/handle/ 10183/7289/000541806.pdf?...1>. Acesso em: 04 de jun. 2014.

MÁRIO JÚNIO, R.J; NARVAI, P. C. Aspectos Históricos e perspectivas da fluoretação de águas de abastecimento público no Estado de São Paulo. Bepa, 2011. P. 24-29.

MULLEN, J. History of water fluoridation. British Dental Journal, v. 199, n. 7, [supl], p. 1-4, 2005.

MULLENIX, P.J.; DENBESTEN, P.K.; SCHUNIOR, A.; KERNANS, W.J. Neurotoxicity of sodium fluoride in rats. Neurotoxicol Teratol, v.17, n.2, p.169-77, 1995.

RAMIRES, I.; BUZALAF, M. A. R. A fluoretação da água de abastecimento público e seus benefícios no controle da cárie dentária - cinquenta anos no Brasil.Ciência e Saúde Coletiva, Rio de Janeiro, v. 12, n. 4,p. 1057-1065, 2007.

SILVA, M.F.A. Flúor: Metabolismo, Toxicologia, Fluorose e Cárie. In: KRIGER L.Promoção de Saúde Bucal. São Paulo: Artes Médicas, 2003. p.153-179.

SPITTLE, B. Psycopharmacology of fluoride: a review. Int Clin Psychopharmacol, v.9, p.79-82, 1994.

THE BRITISH FLUORIDATION SOCIETY, THE UK PUBLIC HEALTH 
Prado, J. R. S., Nunes, J. G., Hinnah, S. S. e Marchetto, M. Fluoretação em água de abastecimento e a saúde pública. E\&S - Engineering and Science, (2014), 2:1.

ASSOCIATION, THE BRITISH DENTAL ASSOCIATION e THE FACULTY OF PUBLIC HEALTH. One in a Million: The extent of water fluoridation. 2. Ed. England: 2004.

WHITFORD, G.M. The physiological and toxicological characteristics of fluoride. J.Dent Res, v.69, p.539-49, 1990.
WHO (Word Health Organization). Fluorides. Environmental Health Criteria 227. Genev. United Nations Environmental Programme, International a Labour Organization, World Health Organization, 274 p., 2002. 